\title{
Superior Mediastinal Lymph Node Group (Level VII)
}

National Cancer Institute

\section{Source}

National Cancer Institute. Superior Mediastinal Lymph Node Group (Level VII). NCI

Thesaurus. Code C132515.

Lymph nodes in this group include pretracheal, paratracheal, and esophageal groove lymph nodes, extending from the level of the suprasternal notch cephalad and up to the innominate artery caudad. These nodes are at greatest risk of involvement by thyroid cancer and cancer of the esophagus. (AJCC 8th ed.) 